\title{
Novel silane encapsulation system for tribochemical resin bonding to a Co-Cr alloy
}

DOI:

10.1016/j.jdent.2016.05.002

\section{Document Version}

Accepted author manuscript

Link to publication record in Manchester Research Explorer

\section{Citation for published version (APA):}

Pilo, R., Dimitriadi, M., Silikas, N., \& Eliades, G. (2016). Novel silane encapsulation system for tribochemical resin bonding to a Co-Cr alloy. Journal of Dentistry, 50, 60-68. https://doi.org/10.1016/j.jdent.2016.05.002

\section{Published in:}

Journal of Dentistry

\section{Citing this paper}

Please note that where the full-text provided on Manchester Research Explorer is the Author Accepted Manuscript or Proof version this may differ from the final Published version. If citing, it is advised that you check and use the publisher's definitive version.

\section{General rights}

Copyright and moral rights for the publications made accessible in the Research Explorer are retained by the authors and/or other copyright owners and it is a condition of accessing publications that users recognise and abide by the legal requirements associated with these rights.

\section{Takedown policy}

If you believe that this document breaches copyright please refer to the University of Manchester's Takedown Procedures [http://man.ac.uk/04Y6Bo] or contact uml.scholarlycommunications@manchester.ac.uk providing relevant details, so we can investigate your claim.

\section{OPEN ACCESS}




\title{
Novel silane encapsulation system for tribochemical resin bonding to a Co-Cr alloy
}

\author{
Raphael Pilo ${ }^{\mathrm{a}}$, Maria Dimitriadi ${ }^{\mathrm{b}}$, Nick Silikas ${ }^{\mathrm{c}}$, George Eliades ${ }^{\mathrm{b}, *}$ \\ a Department of Prosthodontics, School of Dentistry, Tel Aviv University, Israel \\ ${ }^{\mathrm{b}}$ Department of Biomaterials, School of Dentistry, University of Athens, Greece \\ c Dental Biomaterials, School of Dentistry, University of Manchester, UK,
}

\section{A R T I C L E I N F O}

\section{Article history:}

Received 8 March 2016

Received in revised form 2 May 2016

Accepted 5 May 2016

Available online $\mathrm{xxx}$

\begin{abstract}
A B S T R A C T
Objectives: Encapsulated silane has been introduced in powders for tribochemical coating (SilJet Plus, SP), eliminating the need for a separate silane primer. The aim of the study was to comparatively evaluate the effect of SP on the surface properties and bond strength of a $\mathrm{Co}-\mathrm{Cr}$ alloy with a resin composite.

Methods: Co-Cr cast alloy disks were subjected to tribochemical treatments with CoJet (CJ), SilJet (SJ) and SP. Polished specimens were used as control (CR). The alloy surfaces were studied by optical profilometry (OIP; parameters Sa,Sz,Sdr,Sci), reflection FTIR microscopy (RFTIRM; CR,CJ,SJ silanized with S-Bond), scanning electron microscopy/energy dispersive X-ray microanalysis (SEM/EDX; $\mathrm{Al}+\mathrm{Si}$ coverage), contact angle with water (CW) and shear bond strength with a flowable resin composite (SBS). Statistical analysis for OIP, $\mathrm{Al}+\mathrm{Si}$ coverage, CW and SBS was performed by one-way ANOVA and Holm-Sidak multiple comparison tests and by Chi-square for the failure mode $(\alpha=0.05)$.

Results: CR demonstrated the lowest Sa,Sz,Sdr values from all sandblasted surfaces, excluding Sci of SJ. Among tribochemical treatments, no differences were found in $\mathrm{Sa}, \mathrm{Sz}$. $\mathrm{CJ}$ showed lower Sdr and SJ higher Sci. The peaks of $\mathrm{Si}-\mathrm{O}$ - were very weak on CR, but detectable on CJ, SJ and SP, with no evidence of $\mathrm{Si}-\mathrm{O}-\mathrm{CH}_{3}$ groups. The ranking of the statistical significant differences in $\mathrm{CW}$ measurements was $\mathrm{SP}>\mathrm{SJ}+$ silane $>\mathrm{CJ}+$ silane $>\mathrm{CR}+$ silane. Well-defined $\mathrm{Al}$ and diffuse $\mathrm{Si}$ distributions were found on the alloy surface following tribochemical treatments. The maximum $\mathrm{Al}+\mathrm{Si}$ coverage ranged between 50 and $54 \%(5000 \times)$ and the random coverage between 7 and $11 \%(1000 \times, p>0.05$ for both). Tribochemical treatments showed higher SBS from CR $(\mathrm{p}<0.05)$, but with no statistically significant differences among them. CR demonstrated exclusively adhesive failures, whereas in tribochemically coated groups adhesive failures ranged from 10 to $20 \%$.

Clinical significance: Tribochemical treatments with encapsulated silane may be considered an efficient single-step alternative to conventional two-step systems for bonding to $\mathrm{Co}-\mathrm{Cr}$ alloys, offering a significant reduction in chairside time.
\end{abstract}

(๖) 2016 Elsevier Ltd. All rights reserved.

\section{Introduction}

Tribochemical coating of metal substrates by air-blasting silicacoated alumina particles has been shown to be an effective treatment to promote bonding between metal and composite resins in repair processes of fractured metal-ceramic restorations $[1,2]$. This method was found superior to other silica-coating modalities, such as silica-lasing [3] and proved effective for

\footnotetext{
* Corresponding author at: Department of Biomaterials, School of Dentistry, National and Kapodistrian University of Athens, 2 Thivon St Goudi, 11527 Athens, Greece.

E-mail addresses: geliad@dent.uoa.gr, gel@ath.forthnet.gr (G. Eliades).
}

bonding to $\mathrm{Ni}-\mathrm{Cr}$ [4] as well as noble alloys [5], although for the latter inconsistent results have been reported [5].

Following grit-blasting, a dry field and extended silane reaction periods (waiting up to $5 \mathrm{~min}$ ) have been proposed for efficient surface priming [6]. The reaction period is critical because it contributes to solvent evaporation, thin silane film formation to enhance bonding with the substrate rather than intermolecular bonding [7], and removal of the condensation reaction by-products [8]. Nevertheless, reaction periods of 1-7 min following silanization, failed to significantly differentiate bond strength with resin composites. It has been postulated that the determinant factor for increased interfacial strength is the thickness of the siloxane layer formed, which depends on the silane solution concentration, rather than the reaction period [8]. 
All the powders used for intraoral tribochemical coating are based on $30 \mu \mathrm{m}$ silica-coated alumina particles. Recently, silane encapsulation technology was introduced, for simultaneous tribochemical coating and silanization. This technology includes porous silica microcapsules of $\sim 30 \mu \mathrm{m}$ wall thickness, filled with $\gamma$-methacryloxypropyl trimethoxysilane (MPTS), and sealed by superficial MPTS condensates [9]. This single-step treatment provides several advantages over the conventional two-step procedures, including reduced chairside time, better reproducibility, no drying period and therefore, a more compatible surface to adhesion of resin composites.

The aim of the present study was to investigate the effects of a tribochemical bonding system based on encapsulated silane on the surface properties of a Co-Cr alloy, in comparison with conventional tribochemical systems. The null hypothesis was that there are no differences in the surface properties of the alloy among the various treatments.

\section{Materials and methods}

The materials used in the study are listed in Table 1.

Disk-shape specimens $(\varnothing=10 \mathrm{~mm}, \mathrm{~h}=2 \mathrm{~mm}, \mathrm{n}=20)$ were prepared from cast $\mathrm{Co}-\mathrm{Cr}$ alloy, metallographically groundpolished (SiC papers, 320-1000 grit size) in a grinding-polishing machine (Ecomet III, Buehler, Lake Bluff, IL, USA) and ultrasonicated ( $5 \mathrm{~min}$, distilled $\mathrm{H}_{2} \mathrm{O}$ ). The specimens were then randomly assigned into four groups ( $n=5$ per group) of tribochemically-coating treatments CoJet (CJ), SilJet (SJ), SilJet Plus (SP) and a control of untreated polished alloy (CR). The central part of CJ, SJ and SP specimens was grit-blasted with the corresponding powder employing an intraoral sandblaster (Microetcher IIA, Danville Materials) operated at 2.3 bar air pressure $(0.47 \mathrm{~L} / \mathrm{s}$ flow rate), from $5 \mathrm{~mm}$ distance at $90^{\circ}$ angle for $5 \mathrm{~s}$. All the specimens were dried with a stream of dry, oil-free air for $20 \mathrm{~s}$ and then examined by optical interferometric profilometry (OIP), reflection FTIR microscopy (RFTIRM), and scanning electron microscopy/ energy dispersive X-ray microanalysis (SEM/EDX).

For OIP analysis an optical profiler (Wyko NT1100, Veeco, Tuscon, AZ, USA) was used on control and grit-blasted surfaces. Measurements were performed under the following conditions: Mirau lens, $40 \times$ magnification, vertical scanning mode at $10 \mathrm{~mm}$ length, $113.3 \times 148.5 \mu \mathrm{m}^{2}$ analysis area, tilt correction with $0.1 \mathrm{~nm}$ (z-axis) and $0.2 \mathrm{~mm}$ (x-axis and $\mathrm{y}$-axis) resolution. The surface roughness parameters measured were (i) $\mathrm{Si}-\mathrm{O}-\mathrm{C}$ the amplitude parameters Sa (the arithmetic average of the absolute values of the surface height deviations measured from the best fitting plane) (ii) $\mathrm{Sz}$ (the 10 point height over the surface, representing the average difference between the 5 highest peaks and 5 lowest valleys), (iii) the hybrid parameter Sdr (the developed area due to the surface texture vs an ideal plane area ratio) and (iv) the functional parameters Sci (the core fluid retention index, describing the volume that a surface would support from $5 \%$ to $80 \%$ of the bearing ratio in relation to the standard deviation of the height distribution-Sq). Three measurements were performed on each specimen (CR, CJ, SJ, SP groups, $n=5$ per group) and averaged as a specimen representative value.

For RFTIRM analysis, an FTIR microscope (Autolmage, PerkinElmer, Beaconsfield, Bacon, UK) was used attached to an FTIR spectrometer (Spectrum GX, Perkin-Elmer) operated under the following conditions: Liquid $\mathrm{N}_{2}$-cooled mercury-cadmium telluride (MCT) detector, $4000-650 \mathrm{~cm}^{-1}$ wavenumber range, $4 \mathrm{~cm}^{-1}$ resolution, $400 \times 300 \mu \mathrm{m}^{2}$ aperture and 100 scans co-addition per site. Spectra acquisition and interpretation were performed by AutoImage 5.0/Spectrum 5.0.1 software (Perkin-Elmer). All spectra were subjected to Kramers-Kroning and baseline corrections. Measurements were performed at two randomly selected regions on each specimen ( $\mathrm{n}=2$ per group) after sandblasting and silane application (CR, CJ, SJ groups) plus $1 \mathrm{~h}$ storage at $37^{\circ} \mathrm{C}$ (all groups). For silane treatments, S-Bond was applied on the grit-blasted regions using a microfiber brush, left undisturbed for $60 \mathrm{~s}$ and then air-dried for $10 \mathrm{~s}$. The $1250-900 \mathrm{~cm}^{-1}$ wavenumber range was defined as the region of interest, since the major $\mathrm{Si}-\mathrm{O}-\mathrm{C}$ and $\mathrm{Si}-\mathrm{O}-\mathrm{Si}$ vibrations appear at this region [10]. The absorbance spectra recorded, were further subjected to Gaussian peak fitting at standard width/variable shape mode and $3 \%$ zero baseline. Peak fitting analysis was performed by PeakFit v4.12 software (Seasolve, Framingham, MA, USA) and goodness of the fit was assessed by $\mathrm{r}^{2}$ and sum of squares due to error (SSE) parametric models.

For SEM/EDX analysis the specimens (CR, CJ, SJ, SP groups, $\mathrm{n}=3$ per group) were examined in a SEM (Quanta 200, FEI, Hilsboro, OR, USA) coupled to an energy dispersive X-ray spectrometer (Sapphire CDU, EDAX Int, Mahwah, NJ, USA) employing a liquid $\mathrm{N}_{2}$-cooled $\mathrm{Si}(\mathrm{Li})$ detector with a super ultra-thin Be window (SUTW+, EDAX Int). Secondary (SE) and atomic number contrast backscattered electron images (BE) of selective regions were acquired in the SEM at $15 \mathrm{kV}$ accelerating voltage and $90 \mu \mathrm{A}$ beam current in high vacuum mode $\left(5 \times 10^{-6} \mathrm{~Pa}\right)$ under $1000 \times$ magnification. The specimens were further subjected to elemental analysis by the EDX system. Spectra were collected from each region of interest in area scan mode $(15 \mathrm{kV}$ accelerating voltage,

Table 1

The materials used in the study (composition according to manufacturers' information).

\begin{tabular}{|c|c|c|}
\hline PRODUCT & COMPOSITION & MANUFACTURER \\
\hline \multicolumn{3}{|l|}{ TRIBOCHEMICAL SYSTEMS } \\
\hline $\begin{array}{l}\text { CoJet } \\
\text { (Lot: } 385026)\end{array}$ & $30 \mu \mathrm{m}$ silica/alumina particles & 3 M ESPE, Seefeld, Germany \\
\hline SilJet Plus (Lot:112148B) & $\begin{array}{l}30 \mu \mathrm{m} \text { silica/alumina particles, } \\
\text { silica-encapsulated } \gamma \text {-methacryl oxypropyl trimethoxy silane ( } \gamma \text {-MPTS) }\end{array}$ & Danville Materials Inc, S. Ramon, CA, USA \\
\hline SilJet (Lot: 078-096B) & $30 \mu \mathrm{m}$ silica/alumina particles & Danville Materials Inc, S. Ramon, CA, USA \\
\hline \multicolumn{3}{|l|}{ SILANE } \\
\hline S-Bond (Lot:19620) & $\gamma$-MPTS, ethanol & Danville Materials Inc, S. Ramon, CA, USA \\
\hline \multicolumn{3}{|l|}{ ALLOY } \\
\hline Girobond NBS & Co:62-63,Cr:25-26, W:5-5.4, Mo:4.9-5.3, Si:0.9-1.3, Fe, Nd, N<1 (wt\%) & $\begin{array}{l}\text { Amann Gierrbach GmbH, Pforzheim, } \\
\text { Germany }\end{array}$ \\
\hline \multicolumn{3}{|l|}{ COMPOSITES } \\
\hline $\begin{array}{l}\text { Accolade Opaquer TC (079- } \\
\text { 021C) }\end{array}$ & $\begin{array}{l}\text { Bisphenol-A glycidyl dimethacrylate (BisGMA). Ba-glass, amorphous } \mathrm{SiO}_{2} \text { ( } 50 \% \text { wt, } 0.7 \mu \mathrm{m} \\
\text { size) }\end{array}$ & Danville Materials Inc, S. Ramon, CA, USA \\
\hline StarFlow A2 (19887) & BisGMA, Ba-glass, amorphous $\mathrm{SiO}_{2}(61 \%$ wt, $0.7 \mu \mathrm{m}$ size $)$ & Danville Materials Inc, S. Ramon, CA, USA \\
\hline
\end{tabular}


$110 \mu \mathrm{A}$ beam current), $130 \times 120 \mu \mathrm{m}^{2}$ analysis area at $1000 \times$ magnification, $34 \%$ detector dead time and $131.4 \mathrm{eV}$ resolution. EDX spectra were subjected to $C$ and ZAF (atomic number, absorption, fluorescence) corrections. Qualitative and quantitative elemental analysis was performed in non-standard mode utilizing a software (Genesis v 5.2, EDAX Int). Elemental mappings of Al and Si were recorded under $5000 \times$ and $1000 \times$ magnifications and the area coverage by $\mathrm{Al}+\mathrm{Si}$ was calculated at regions with maximum $\mathrm{Al}$ and Si distributions $(5000 \times)$ and at randomly chosen regions $(1000 \times)$. The same conditions were used for the analysis of the powders, at $500 \times$ magnification, which were pressed against an aluminum stab covered with self-adhesive graphite tape.

A second series of 15 specimens per group were prepared as above. Five specimens per group were used to evaluate the wettability of the silane treated surfaces with distilled water and the rest for assessment of the shear bond strength with a resin composite. The wettability study was performed by the sessile drop method. Briefly, a $5 \mu \mathrm{L}$ triple-distilled water drop was applied by a micro syringe on SP and silane-treated CR, CJ, SJ specimen surfaces placed horizontally on an adjustable (x,y, z-tilt) micrometric table. After $10 \mathrm{~s}$, the meniscus of the droplet formed was photographed with a digital camera under ambient conditions $\left(23^{\circ} \mathrm{C}, 60 \% \mathrm{RH}, 1: 1\right.$ magnification) by focusing at the highest meridian plane of the drop section that intersects the equilibrium three-phase line [11]. The contact angle $(\theta)$ was measured trigonometrically $(\theta=2 \operatorname{arctn} 2 \mathrm{~h} / \mathrm{b}$, where $\mathrm{h}$ the height and $\mathrm{b}$ the base length of the meniscus). This method is considered suitable for small drops [11]. One photograph was taken per specimen, since top-view images showed that the droplet was symmetric about a central vertical axis.

For the shear bond strength study (SBS), the SP and silanetreated CR, CJ and SJ specimen surfaces were covered with a $100 \mu \mathrm{m}$-thick masking tape, leaving free circular areas $(\varnothing=2 \mathrm{~mm})$. All treated surfaces were covered with a thin layer $(\sim 0.1 \mathrm{~mm}$ thickness) of a light-cured opaquer (Accolade Opaquer TC), which was irradiated for $20 \mathrm{~s}$. Then, cylindrical molds $(\varnothing=2.4 \mathrm{~mm}$, $\mathrm{h}=2 \mathrm{~mm}$ ) were placed over the treated surfaces, filled with a light-cured flowable composite (StarFlow, A2 shade), and irradiated for $30 \mathrm{~s}$. Irradiation was performed with a LED curing unit (Bluephase 16i, Ivoclar Vivadent, Schaan, Liechtenstein) operated in standard mode ( $1600 \mathrm{~mW} / \mathrm{cm}^{2}$ irradiance with turbo tip). All specimens were stored in distilled water $\left(5\right.$ days $\left./ 37^{\circ} \mathrm{C}\right)$, then subjected to thermal-cycling in water $\left(3000 \times, 5 / 55^{\circ} \mathrm{C}, 2\right.$ cycles/ min, $10 \mathrm{~s}$ dwell time, $5 \mathrm{~s}$ transfer time) and debonded under shear loading (notched-edge blade method) in a universal testing machine (Tensometer 10, Monsanto, Swindon, UK) operated at $1.0 \mathrm{~mm} / \mathrm{min}$ crosshead speed. Debonded metal surfaces were subjected to failure mode analysis under a stereomicroscope (M80, Leica Microsystems, Wetlzar, Germany) at $10 \times$ magnification. Failure mode was classified as follows: Type I (adhesive at the alloy-composite interface), Type II (cohesive within the composite) and Type III (mixed, type I and II).

Statistical analyses of the roughness parameters, surface wettability by water, extent of $\mathrm{Al}+\mathrm{Si}$ surface coverage and SBS were performed by one-way ANOVA plus Holm-Sidak multiple comparison tests and by Chi-square test for failure mode analysis $(\alpha=0.05)$.

\section{Results}

Representative 3D-roughness images of the control (CR) and the grit-blasted surfaces (CJ, SJ, SP) are illustrated in Fig. 1. All the grit-blasting treatments completely modified the alloy surface by eliminating the original polishing tracks of the control. The results of the roughness parameters tested are summarized in Table 2. The control group (CR) demonstrated significantly lower values of Sa, $\mathrm{Sz}, \mathrm{Sdr}$ from all grit-blasted surfaces $(\mathrm{p}<0.05)$, but no statistically significant difference of Sci compared to SJ $(p=0.12>0.05)$. No statistically significant differences were found among the treatments tested in Sa and Sz. CJ demonstrated significantly lower Sdr
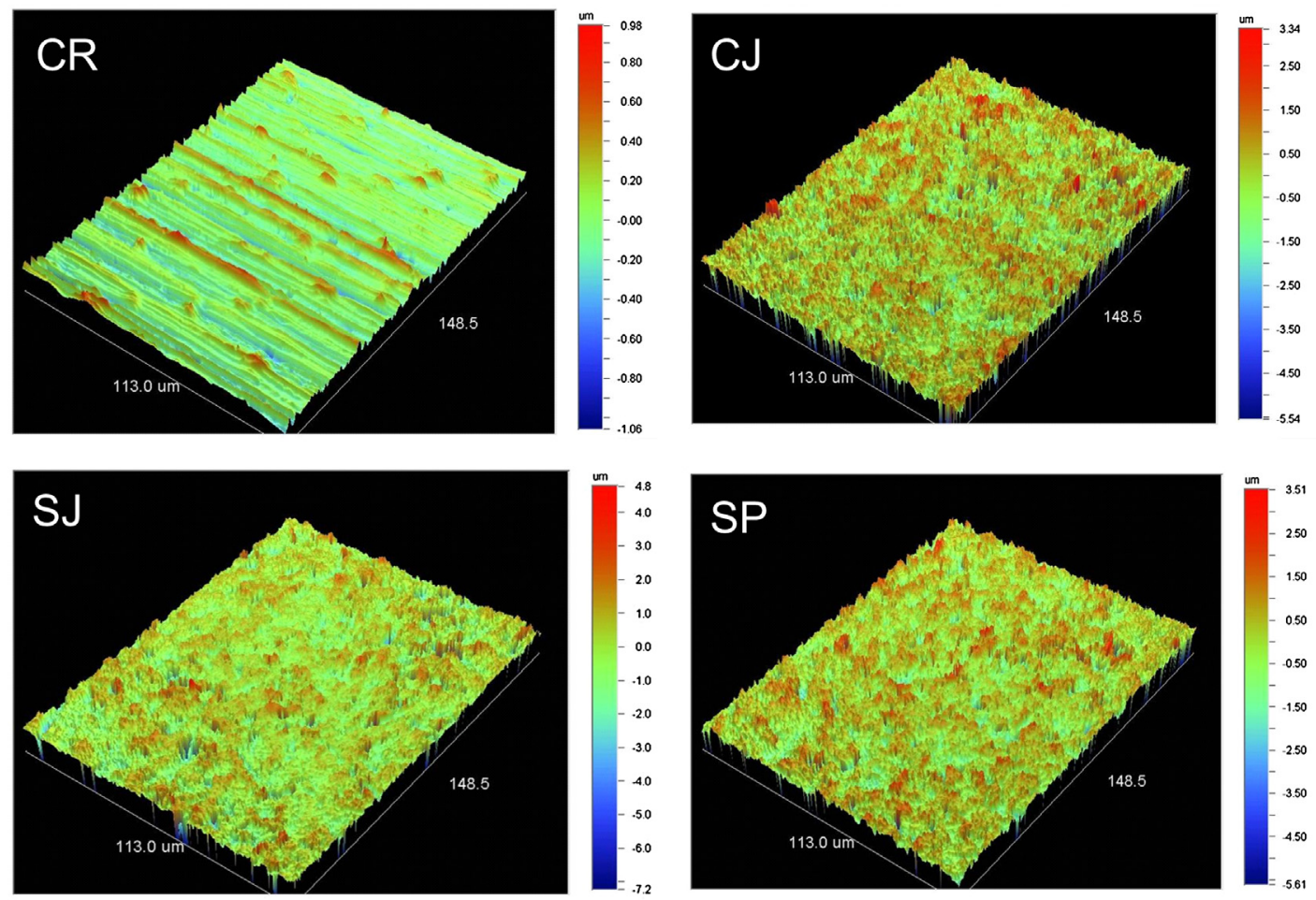

Fig. 1. 3D optical interferometric images of the control and tribochemically coated surfaces (40× magnification).

Please cite this article in press as: R. Pilo, et al., Novel silane encapsulation system for tribochemical resin bonding to a Co-Cr alloy, Journal of Dentistry (2016), http://dx.doi.org/10.1016/j.jdent.2016.05.002 
Table 2

Results (means and standard deviations) of the roughness parameters tested. Same superscripts show means with no statistically significant differences per parameter $(\mathrm{p}>0.05)$.

\begin{tabular}{lllll}
\hline TREATMENT & Sa $(\mu \mathrm{m})$ & Sz $(\mu \mathrm{m})$ & Sdr $(\%)$ & Sci \\
\hline CR & $0.15(0.04)^{\mathrm{a}}$ & $1.59(0.24)^{\mathrm{c}}$ & $3.20(0.18)^{\mathrm{e}}$ & $1.65(0.06)^{\mathrm{h}}$ \\
CJ & $0.55(0.05)^{\mathrm{b}}$ & $5.54(0.22)^{\mathrm{d}}$ & $63.08(1.90)^{\mathrm{f}}$ & $1.32(0.03)^{\mathrm{i}}$ \\
SJ & $0.61(0.04)^{\mathrm{b}}$ & $5.72(0.30)^{\mathrm{d}}$ & $80.68(1.07)^{\mathrm{g}}$ & $1.62(0.03)^{\mathrm{h}}$ \\
SP & $0.56(0.02)^{\mathrm{b}}$ & $5.64(0.13)^{\mathrm{d}}$ & $82.55(1.35)^{\mathrm{g}}$ & $1.30(0.01)^{\mathrm{i}}$ \\
\hline
\end{tabular}

value as compared to SJ and SP, whereas SJ demonstrated higher Sci value as compared to $\mathrm{CJ}$ and $\mathrm{SP}$.

RFTIRM spectra of the treated surfaces are illustrated in Fig. 2. The characteristic peaks of silane (mainly the $\mathrm{Si}-\mathrm{O}-\mathrm{C}$ at $1190 \mathrm{~cm}^{-1}$ and $\mathrm{Si}-\mathrm{O}-\mathrm{Si}$ at the region $1090-1020 \mathrm{~cm}^{-1}$ ) were diminished on metal surface, which demonstrated organic contamination traces of protein $\left(1660,1540 \mathrm{~cm}^{-1}\right)$ and lipid $\left(1800-1740 \mathrm{~cm}^{-1}\right)$ origin. The main $\mathrm{Si}-\mathrm{O}$ stretching vibrations $\left(1090 \mathrm{~cm}^{-1}\right)$ were clearly identified on tribochemically treated surfaces, as a broad peak with higher and lower wavenumber shoulders. To resolve the contribution of the substrate and silane $\mathrm{Si}-\mathrm{O}$ groups to the peak recorded, the $1250-900 \mathrm{~cm}^{-1}$ wavenumber region, which includes most $\mathrm{Si}-\mathrm{O}$ - vibrations, was subjected to Gaussian deconvolution (Fig. 3). The original silane peaks at 1107 and $1078 \mathrm{~cm}^{-1}$ were identified on CJ and SJ, but were shifted by $-10 \mathrm{~cm}^{-1}$ in $\mathrm{SP}\left(1097\right.$ and $\left.1067 \mathrm{~cm}^{-1}\right)$. The $\mathrm{Si}-\mathrm{O}-\mathrm{CH}_{3}$ peak found in the original silane $\left(1182 \mathrm{~cm}^{-1}\right)$ was not identified on CJ, SJ and SP surfaces, suggesting adequate silane hydrolysis. The $\mathrm{C}-\mathrm{H}$ bending out of plane $\mathrm{CH}_{2}=\mathrm{C}<$ vibrations $\left(975 \mathrm{~cm}^{-1}\right)$ were traced in all sandblasted surfaces, denoting the presence of $\mathrm{C}=\mathrm{C}$ bonds from the MPTS. Changes in the relative intensities of the peaks may imply variations in the silane coating capacity.

Photographs of the contact angle of the treated surfaces with water are presented in Fig. 4. The results are given in Table 3. The ranking of the statistically significant differences in the contact angle $\theta$ was $\mathrm{SP}>\mathrm{SJ}+$ Silane $>\mathrm{CJ}+$ Silane $>\mathrm{CR}+$ Silane $(\mathrm{p}<0.001)$. The surface left after SP was the most hydrophobic, whereas the silanated control alloy surface was the most hydrophilic. Representative SE images of the reference and tribochemically treated surfaces are illustrated in Fig. 5. The morphological features of the surfaces treated with SJ and SP were more pronounced that CJ. All the treatments completely modified the SiC polished alloy morphology. The BE images showed regions with different grayscale corresponding to different phases. EDX analysis showed that most of the low grayscale (darker regions) corresponded to $\mathrm{Si}$ and $\mathrm{Al}$ distributions (Fig. 6). The results of the maximum (Fig. 6) and random (Fig. 7) percentage surface area coverage by $\mathrm{Al}+\mathrm{Si}$ are summarized in Table 3 . There were no statistically significant differences among the tribochemical treatments in maximum $(p=0.73>0.05)$ or random mean values $(p=0.14>0.05)$. No Al $+\mathrm{Si}$ coverage values could be determined for CR. The EDX analysis of the three powders showed higher $\mathrm{Si} / \mathrm{Al}$ atomic ratio in $\mathrm{CJ}(0.13)$ in comparison with SJ (0.03) and SP (0.06).

The results of SBS testing and failure mode analysis are presented in Table 4. No statistically significant differences were found in the SBS values among the tribochemical treatments tested. All these treatments demonstrated significantly higher values from the control $(\mathrm{p}<0.001)$, which demonstrated exclusively adhesive (Type I) failures. In the tribochemically-treated groups the cohesive resin failures ranged from 30 to 50\%, whereas the mixed from 40 to $50 \%$. There was no statistically significant difference in the failure mode among these groups $(p>0.05)$

\section{Discussion}

The tribochemical systems tested have been introduced for chairside procedures related to repair of metal-ceramic, metalpolymer or composite restorations $[2,12,13]$ and for the treatment

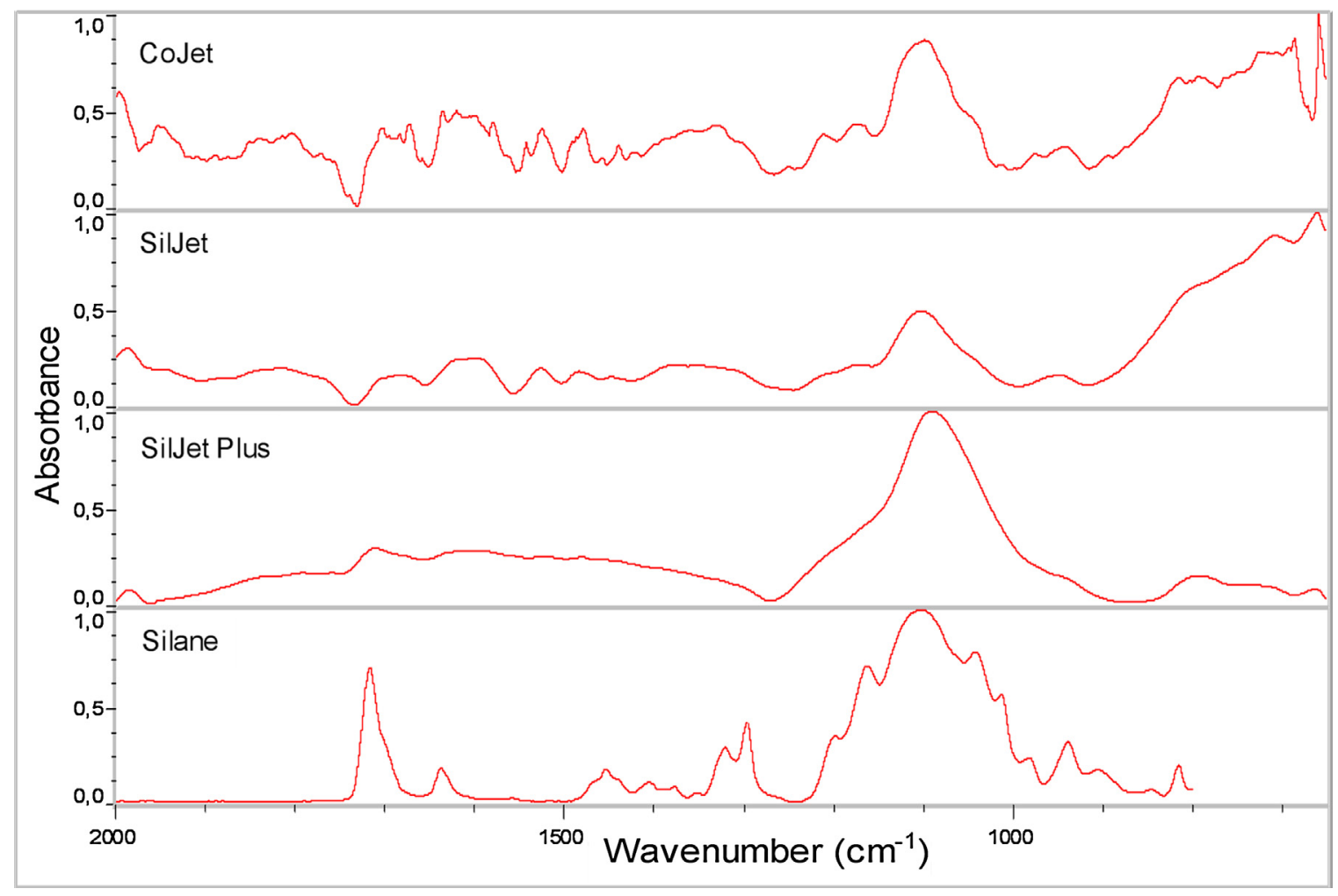

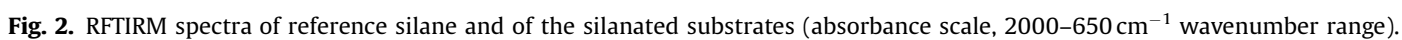



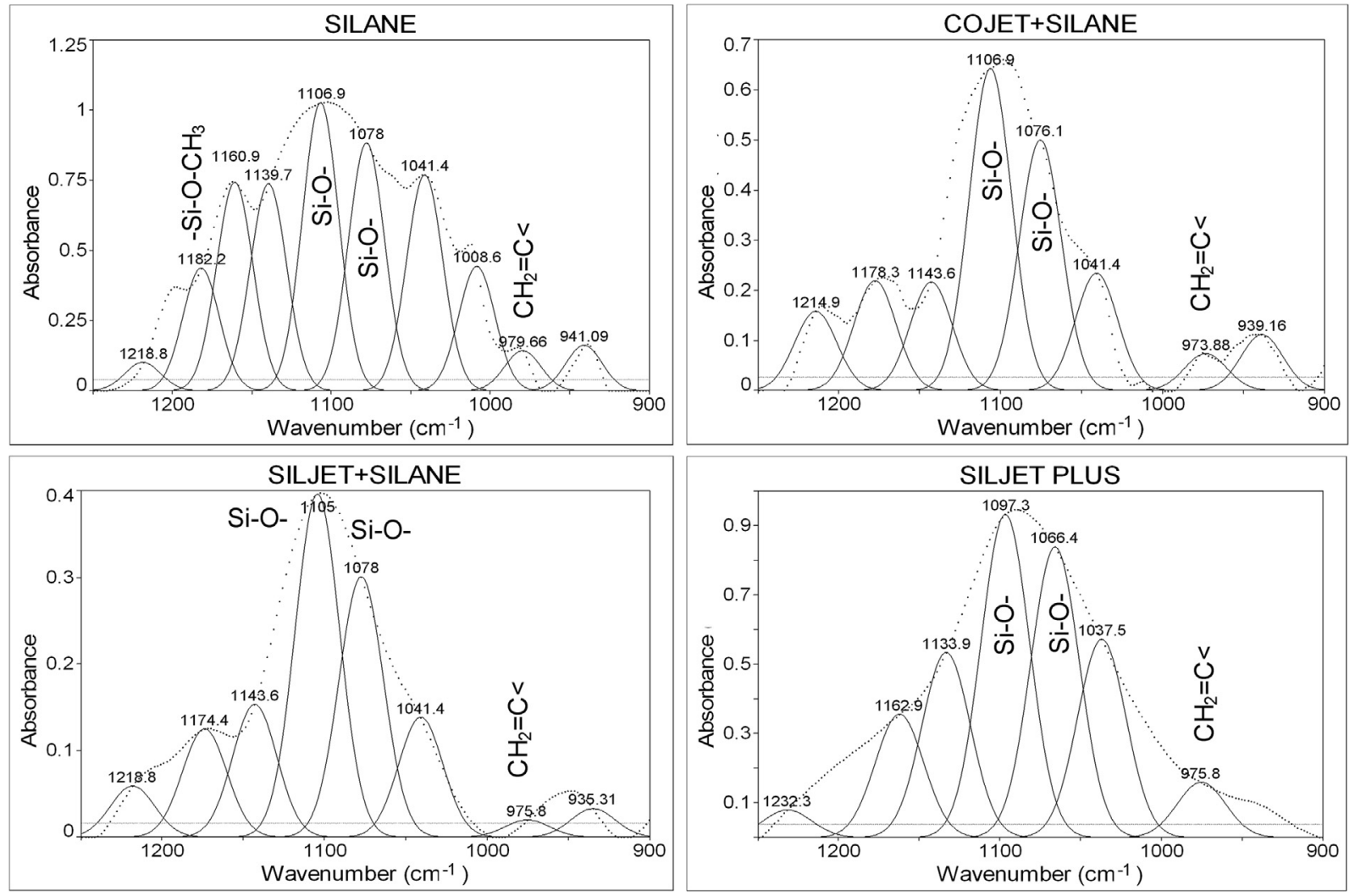

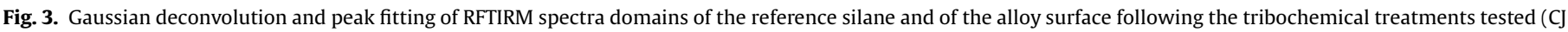

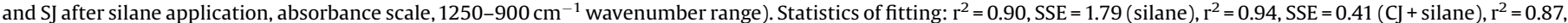
$\mathrm{SSE}=0.57(\mathrm{SJ}+$ silane $)$, and $\mathrm{r}^{2}=0.85, \mathrm{SSE}=1.36(\mathrm{SP})$

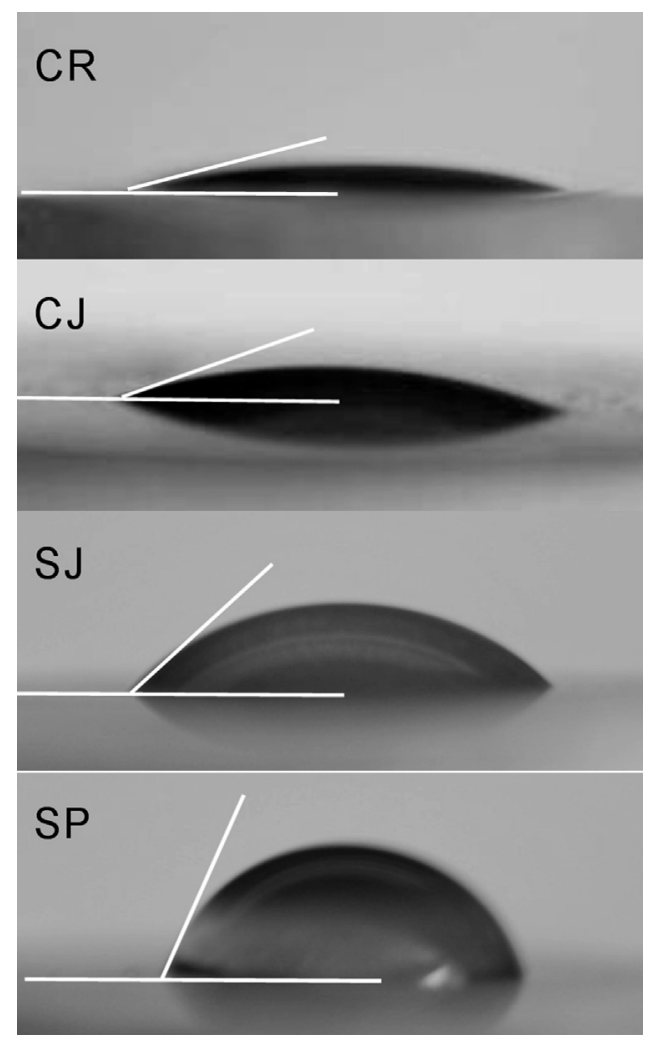

Fig. 4. Water contact angles on the control (CR) and following the tribochemical treatments CJ, SJ and SP. of metal, composite and ceramic bonding surfaces of indirect restorations. Comparison of the chairside with the well-established laboratory tribochemical coating procedures showed a similar performance in regard to the bond strength of resin composites to glass-infiltrated ceramics [14], alumina based ceramics [15] or zirconia. For the latter, particle size of $\leq 50 \mu \mathrm{m}$ is recommended to avoid destabilization of the tetragonal phase [16]. However, as concerning alloy surfaces, there are conflicting results. For titanium, there is evidence of superior performance of the laboratory devices [17,18], although this has not been confirmed in other studies [19]. For base and noble alloys, the results available are contradictory [20,2]. According to the manufacturers' information, all the powders used for intraoral tribochemical coating are based on $30 \mu \mathrm{m}$ silica-coated alumina particles, usually produced by sol-gel silica precipitation on alumina particles [9]. In SP, silica microcapsules of $\sim 30 \mu \mathrm{m}$ wall thickness are included, as well. These porous microcapsules, described as silica elongated spheres, are filled during

Table 3

Results (means and standard deviations) of the water contact angle measurements $(\theta)$ and the percentage of $\mathrm{Al}+\mathrm{Si}$ surface area coverage (maximum and random) on the control (CR) and the tribochemically treated alloy surfaces. Measurements on $\mathrm{CR}, \mathrm{CJ}$ and SJ were made after silane treatment. Same superscripts show means with no statistically significant differences $(p>0.05)$.

\begin{tabular}{llll}
\hline TREATMENT & $\theta\left(^{\circ}\right)$ & \multicolumn{2}{l}{ Surface area coverage $(\%)$} \\
\cline { 3 - 4 } & & Maximum $(5000 \times)$ & Random $(1000 \times)$ \\
\hline CR + silane & $17.6(2.5)^{\mathrm{a}}$ & - & - \\
$\mathrm{CJ}+$ silane & $30.8(4.0)^{\mathrm{b}}$ & $53(2)^{\mathrm{e}}$ & $8(2)^{\mathrm{f}}$ \\
SJ + silane & $54.2(4.1)^{\mathrm{c}}$ & $50(9)^{\mathrm{e}}$ & $7(2)^{\mathrm{f}}$ \\
SP & $73.4(2.8)^{\mathrm{d}}$ & $54(7)^{\mathrm{e}}$ & $11(4)^{\mathrm{f}}$ \\
\hline
\end{tabular}

Please cite this article in press as: R. Pilo, et al., Novel silane encapsulation system for tribochemical resin bonding to a Co-Cr alloy, Journal of Dentistry (2016), http://dx.doi.org/10.1016/j.jdent.2016.05.002 


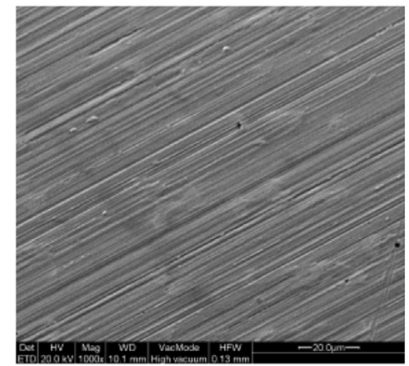

CR (SE)

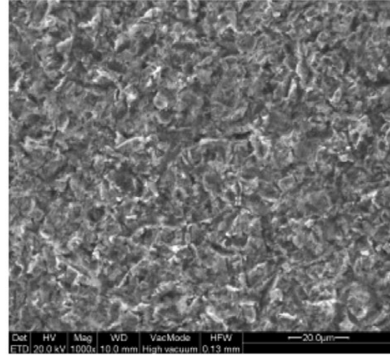

CJ (SE)

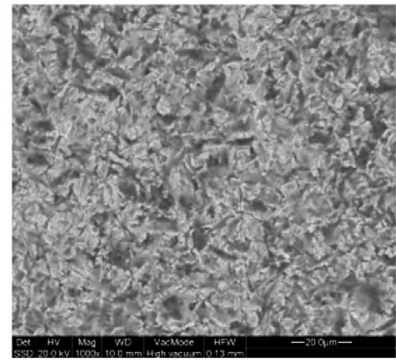

$\mathrm{CJ}(\mathrm{BE})$

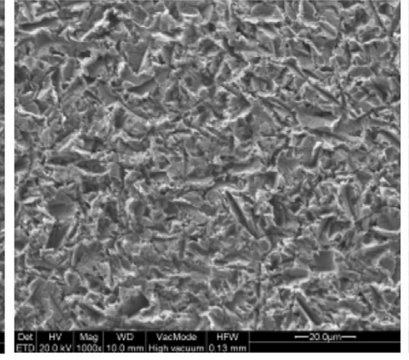

SJ (SE)

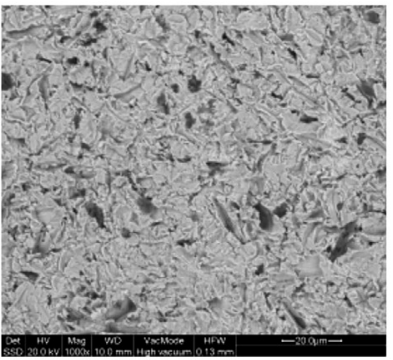

SJ (BE)

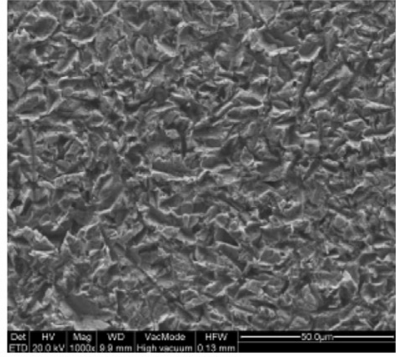

SP (SE)

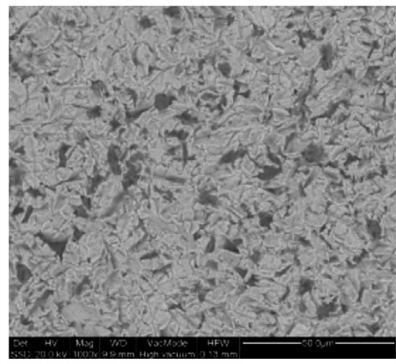

$\mathrm{SP}(\mathrm{BE})$

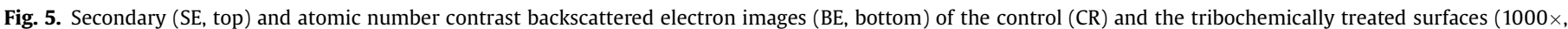
bar $=20 \mu \mathrm{m})$.

manufacturing with MPTS and sealed by the superficial MPTS condensates formed at pore orifices in contact with environmental humidity [9]. Therefore, the airborne particles of SP have the capacity of simultaneous roughening, silica implantation and silanization of the target, as opposed to $\mathrm{CJ}$ and SJ, where a separate silanization step is required. The EDX analysis of the three powders showed differences in the $\mathrm{Si} / \mathrm{Al}$ atomic ratios of the tribochemical powders used. However, on the tribochemically treated alloy surfaces the Si/Al atomic ratios were similar after all treatments (1.59-1.61). Considering that the Si content of the alloy was low (0.9-1.3\% in bulk weight), no substrate interferences could account for these results. An explanation could be given based on the presence of isolated fractions of alumina used as carrier particles in the powders tested. The highest Sdr value was obtained after SJ and SP treatments, which possessed the lowest Si/Al atomic ratio (highest $\mathrm{Al}$ content). The excess of alumina in these systems may

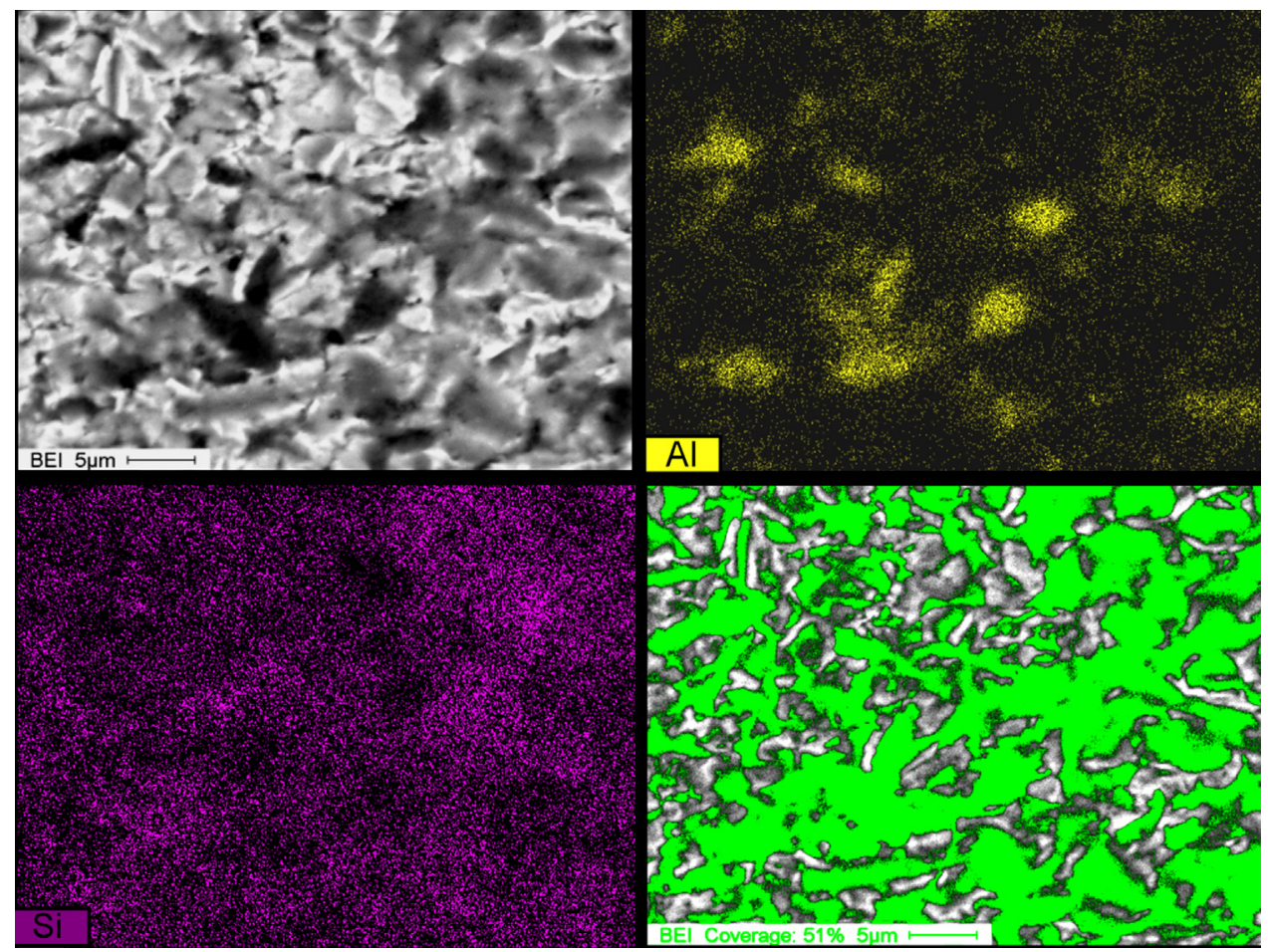

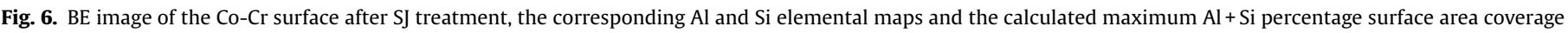
$(5000 \times$, bar $=5 \mu \mathrm{m})$.

Please cite this article in press as: R. Pilo, et al., Novel silane encapsulation system for tribochemical resin bonding to a Co-Cr alloy, Journal of Dentistry (2016), http://dx.doi.org/10.1016/j.jdent.2016.05.002 


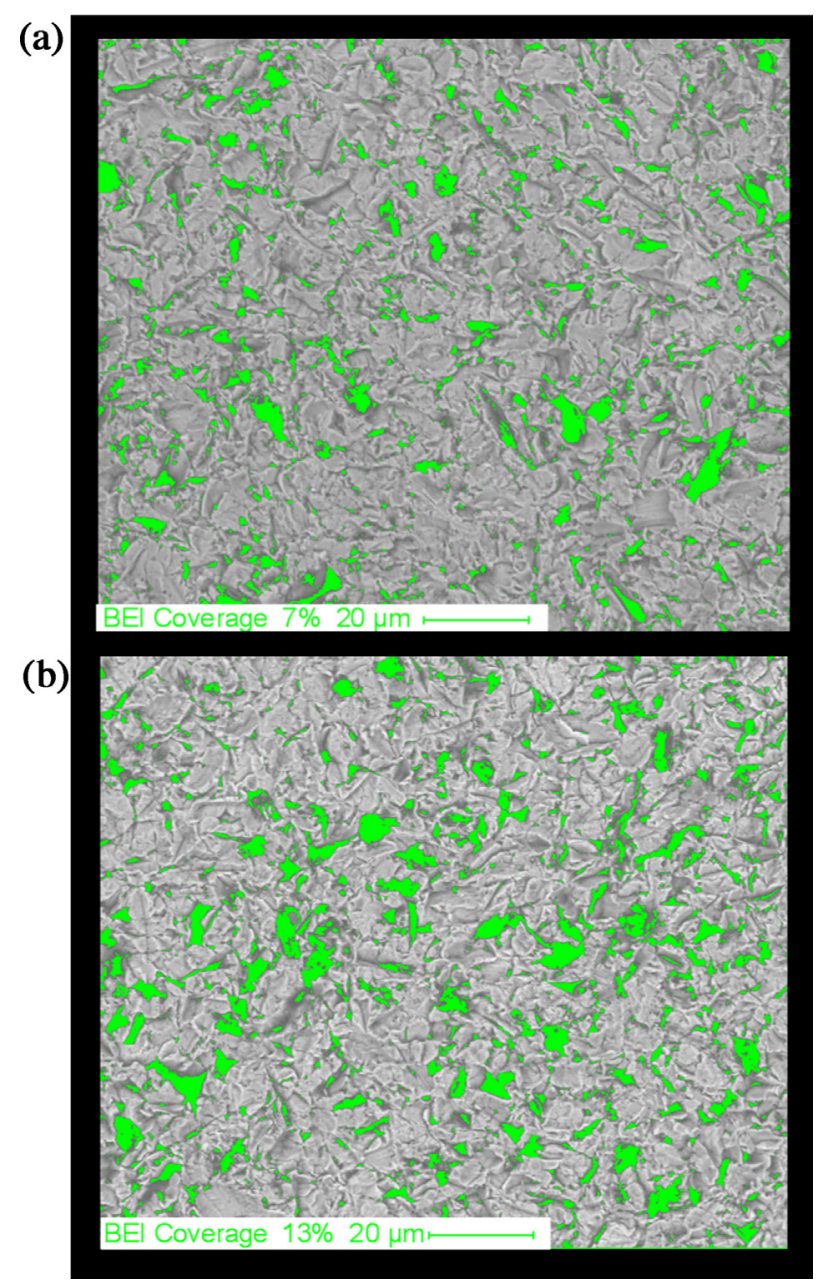

Fig. 7. The random $\mathrm{Al}+\mathrm{Si}$ percentage surface area coverage of the alloy after $\mathrm{SJ}$ (a) and SP (b) treatments (BE images, $1000 \times$, bar $=20 \mu \mathrm{m}$ ).

\section{Table 4}

Results (means, standard deviations, confidence intervals of means-C.I.) of SBS and failure mode analysis (number of specimens per type). Measurements on CR, CJ and SJ were made after silane treatment. Same superscripts show values with no statistically significant differences $(p>0.05)$.

\begin{tabular}{|c|c|c|c|c|}
\hline \multirow[t]{2}{*}{ TREATMENT } & \multirow{2}{*}{$\begin{array}{l}\text { SBS } \\
(\mathrm{MPa})\end{array}$} & \multicolumn{3}{|c|}{ Failure mode $(\mathrm{n})$} \\
\hline & & Type I & Type II & Type III \\
\hline $\mathrm{CR}+$ silane & $\begin{array}{l}5.6(2.3)^{a} \\
(C . I=1.7)\end{array}$ & 10 & 0 & 0 \\
\hline $\mathrm{CJ}+$ silane & $\begin{array}{l}20.9(2.5)^{b} \\
(\text { C.I. }=2.4)\end{array}$ & $2^{\mathrm{c}}$ & $3^{\mathrm{d}}$ & $5^{\mathrm{e}}$ \\
\hline SJ + silane & $\begin{array}{l}26.1(1.6)^{\mathrm{b}} \\
(\text { C.I. }=1.2)\end{array}$ & $1^{\mathrm{c}}$ & $5^{d}$ & $4^{e}$ \\
\hline SP & $\begin{array}{l}26.4(3.2)^{\mathrm{b}} \\
(\text { C.I. }=2.3)\end{array}$ & $2^{\mathrm{c}}$ & $3^{d}$ & $5^{e}$ \\
\hline
\end{tabular}

not increase the amplitude roughness parameters (Sa, Sz), which are dominated by the particle size and grit-blasting conditions, but may affect the overall surface area produced as defined by Sdr. All the powders used completely modified the morphology of the polished alloy surface, by eliminating the polishing tracks and creating pitting, fissures and a granular surface appearance, as documented by OIP.

The morphological features were more clearly resolved under the SEM and appeared more pronounced in SJ and SP, a finding that is in agreement with the results of OIP. The irregular powder particles induced sharp fissures and occasionally cracking in the complex morphology left after grit-blasting. It has been proposed that each airborne particle hitting the surface reacts like a plowshare and creates shallow and elongated fissures, as the ones identified under the SEM in the present study. This creates tensile forces at the adjacent material surface regions, which are counterbalanced by development of compressive stresses from the subsurface material regions [21]. In the absence of thermal treatments at the region, these residual compressive stresses are expected to remain, since application of resin composites intraorally does not require thermal treatments. Although there is no information for the depth and the properties of the plastically deformed zone, crack development may reduce the interfacial durability, despite the residual compressive stresses.

Retention of alumina fragments on alloy surfaces has long been identified as a major problem of sandblasting, which may affect interfacial strength, even in metal-resin systems [22]. The backscattered images of the treated alloy surfaces showed different phases that corresponded to distributions of $\mathrm{Si}$ and $\mathrm{Al}$, as determined from the EDX analysis. Nevertheless, these distributions did not always correspond to the same region, due to the presence of alumina as a separate phase in the powders. The $\mathrm{Al}+\mathrm{Si}$ covering capacity recorded cannot be considered as an efficient and uniform surface coating treatment. This is especially important for conventional silane primers (free of phosphate monomers), which bond only to the Si-rich fraction of the coating. The $\mathrm{Al}+\mathrm{Si}$ coverage values on the polished alloy (CR) were negligible, since under the EDX acquisition parameters used, the contribution of the Si peak of the silane film was minimal, due to increased alloy excitation, and the lack of $\mathrm{Al}$ content. In addition, the diminished $\mathrm{Si}$ content implies that the alloy surface region probed by EDX was deficient in Si.

Silanization of the CJ and SJ surfaces with MPTS transforms the hydrophilic metal surfaces to hydrophobic, favoring energetically the application of hydrophobic bonding resins and resin composites. The tribochemically treated surfaces demonstrated differences in the molecular composition. The Gaussian deconvolution of CJ and SJ spectra showed similar peaks, but SP revealed an important low-wavenumber shifting of the major $\mathrm{Si}-\mathrm{O}-\mathrm{Si}$ stretching peak. A possible explanation is an increased interference from the silica particles, which when applied in relative thick layers show a peak at $1090 \mathrm{~cm}^{-1}$ [23]. Peak shifting is also affected by the stress status in case of coatings [24]. It seems that in SP, the silane released upon fracture of the microcapsules was intermixed with the implanted silica fragments, creating thus a silane-rich zone and not a distinct surface layer, as in conventional silane application. The differences in the relative intensities may anticipate variations in the coating capacity or film thickness. Nevertheless, performing such measurements is quite a challenging task, since the surfaces left following sandblasting are rough and the silane treatments performed heterogeneously. The RFTIRM analysis did not probe directly the development of chemical bonds with the substrate surface since the sandblasted substrate and the silanol groups bonded to the substrate, share the same chemistry; $\mathrm{Si}-\mathrm{O}-\mathrm{Si}$ for the silica coated surface, the silanol intermolecular condensates and the silanol reaction with the silica coating [25]. This analytical technique was chosen to face the disadvantages of high-vacuum techniques in binding state analysis (strong dehydration, monomer evaporation, propagation of condensation reactions, superficial depth of analysis, etc). In addition, it is a non-contact, non-destructive method and may provide complementary results to SEM/EDX [26].

For the control group (Co-Cr polished alloy surface), the lack of surface silica content was expected to reduce the bonding capacity of the silane with the alloy, since the only possible reaction is via weak hydrogen bonding with the metal surface oxides resulting in 
low SBS with the flowable resin composite. It has been documented that in the absence of silica, such substrates favor complex hydrolytic and condensation reactions of silanes to silsesquioxanes rather than covalent bonding to the substrate [27]. On $\mathrm{Co}-\mathrm{Cr}$ base metal alloys, a rather stable oxide film is formed mainly composed of $\mathrm{Cr}_{2} \mathrm{O}_{3}$, $\mathrm{CoO}$ and $\mathrm{MoO}_{3}$, which is less reactive than the oxide film formed on $\mathrm{Ni}-\mathrm{Cr}$ alloys, consisting of $\mathrm{NiO}, \mathrm{Cr}_{2} \mathrm{O}_{3}$ and $\mathrm{MoO}_{3}$ [28]. The acidic or basic character of the oxide films formed may modify the degree of silane physisorption (adsorption with no covalent bonds) [25] and possibly the extent of weak secondary bonding on these substrates.

Contact angle measurements revealed significant differences among the groups tested. Contact angle values $<20^{\circ}$ should be considered carefully, since they cannot be accurately measured with the set-up used, or any other telescope-goniometer device, because the profile of the drop is almost flat [11]. The polished and silane-treated metal surface was the most hydrophilic substrate, providing the smallest contact angle with water. Apparently, the limited reactivity between the silane and the metal oxides failed to create a well-defined hydrophobic layer to impel water spreading. The rougher alloy surfaces established after CJ, SJ and SP treatments demonstrated greater contact angles with water, although it has been shown that for certain alloy and ceramic surfaces a slight increase in roughness can strongly reduce contact angle [29]. This implies a positive hydrophobic effect of silane treatment on the surface energetics of the sandblasted Co-Cr alloy. The microencapsulated silane incorporated in SP showed the highest contact angle, despite that the surface left had no statistically significant differences from SJ in roughness parameters. A possible explanation is that in SP silanization takes place at a very high temperature produced by the simultaneous sandblasting. Under such conditions the silane-substrate reactions are far more pronounced as they are expected to react with deeply surface bound water or with water-deficient compatible oxides. An additional point that has not been addressed in the present study is the status of the encapsulated silane. Sealing of the microcapsule porosity by ambient water may imply that the encapsulated silane may co-exist in an oligomeric or partially condensed form, embedding thus hydrophobic pre-silananized silica fragments on the substrate upon sandblasting. This issue requires further investigation.

Flowable resin composites (opaque and main restorative) were used for SBS specimen preparation to simulate the clinical conditions and to reduce the possibility of interfacial or bulk air-entrapment into the restorations. The lack of statistically significant differences in the SBS and failure mode among CJ, SJ and SP groups show that the latter is at least equally efficient with the conventional two-step treatments, $\mathrm{CJ}$ and SJ. This is in agreement with the results obtained for SJ and SP on zirconia surfaces, where the two systems demonstrated no statistically significant difference in shear bond strength [30]. Consequently, the method of encapsulated silane in the blasting powder may be provisionally considered as a promising chairside procedure, by eliminating the time required for silane application and drying. The null hypothesis should be partially rejected for the above properties.

Future research should be focused on the performance of this treatment on various substrates $(\mathrm{Ni}-\mathrm{Cr}$, $\mathrm{Ti}$, noble alloys, composites, non-etchable ceramics etc), to validate the capacity of silane microencapsulation in replacing conventional silane primer application.

\section{Conclusions}

According to the findings of the present study, the incorporation of encapsulated silane particles into alumina-silica powders used for tribochemically bonding of a $\mathrm{Co}-\mathrm{Cr}$ alloy with resin- composites, is equally efficient with conventional two-step systems, where a separate silanization phase is instructed. The surface alterations induced on the $\mathrm{Co}-\mathrm{Cr}$ alloy by the silane encapsulated system were similar to conventional systems, except from an increase in the water contact angle and Sdr surface roughness parameter.

\section{Acknowledgements}

The study was supported by Danville Materials Inc., S. Ramon, CA, USA.

\section{References}

[1] M. Özcan, The use of chairside silica coating for different dental applications: a clinical report, J. Prosthet. Dent. 87 (2002) 469-472.

[2] T. Watanabe, S. Ino, S. Okada, Y Katsumata, N. Hamano, S. Hojo, T. Teranaka, M. Toyodo, Influence of simplified silica coating method on the bonding strength of resin cement to dental alloy, Dent. Mater. J. 27 (2008) 16-20.

[3] A.S. Madani, P.A. Astaneh, M. Nakhaei, H.G. Bagheri, H. Moosavi, S. Alavi, N.T. Najjaran, Effectiveness of silica-lasing method on the bond strength of composite resin repair to Ni-Cr alloy, J. Prosthodont. 24 (2015) 225-232.

[4] J.Y. Yoo, H.I. Yoon, J.M. Park, E.J. Park, Porcelain repair-Influence of different systems and surface treatments on resin bond strength, J. Adv. Prosthodont. 7 (2015) 343-348.

[5] C. Robin, S.S. Scherrer, H.W. Wiskott, W.G. de Rijk, U.C. Belser, Weibull parameters of composite resin bond strengths to porcelain and noble alloy using the Rocatec system, Dent. Mater. 18 (2002) 389-395.

[6] J.P. Matinlinna, L.V. Lassila, M. Özcan, A. Yli-Urpo, P.K. Vallittu, An introduction to silanes and their clinical applications in dentistry, Int. J. Prosthodont. 17 (2004) 155-164.

[7] M. Özcan, J.P. Matinlinna, P.K. Vallittu, M.C. Huysmans, Effect of drying time of 3-methacryloxypropyltrimethoxysilane on the shear bond strength of a composite resin to silica-coated base/noble alloys, Dent. Mater. 20 (2004) 586590.

[8] P.J. Grey, Polymerization and surface interaction of a silane coupling agent, in: K.A. Allen (Ed.), Adhesion 12, Elsevier Applied Science Publishers, London, 1988, pp. 106-120.

[9] C. Angeletakis, G. Dorsman, Methods, compositions and apparatus for applying an agent to a dental substrate and uses thereof. US Patent US20140004482.

[10] N. Nishiyama, K. Horie, T. Asakura, Hydrolysis and condensation mechanisms of a silane coupling agent studied by ${ }^{13} \mathrm{C}$ and ${ }^{29} \mathrm{Si} \mathrm{NMR}$, J. Appl. Polym. Sci. 34 (1987) 1619-1630.

[11] H. Yuan, T.R. Lee, Contact angle and wetting properties, in: G. Bracco, B. Holst (Eds.), Surface Science Techniques. Springer Series in Surface Sciences, vol. 51, Springer-Verlag, Berlin Heidelberg, 2013, pp. 3-34.

[12] S.A. Rodrigues Jr., J.L. Ferracane, A. Della Bona, Influence of surface treatments on the bond strength of repaired resin composite restorative materials, Dent Mater. 25 (2009) 442-451.

[13] B.A. Loomans, M.V. Cardoso, F.J. Roeters, N.J. Opdam, J. De Munck, M.C. Huysmans, Van Meerbeek B. Is there one optimal repair technique for all composites? Dent. Mater. 27 (2011) 701-709.

[14] R. Amaral, M. Ozcan, M.A. Bottino, L.F. Valandro, Microtensile bond strength of a resin cement to glass infiltrated zirconia-reinforced ceramic: the effect of surface conditioning, Dent. Mater. 22 (2006) 283-290.

[15] L.F. Valandro, F.P. Leite, R. Scotti, M.A. Bottino, M.P. Niesser, Effect of ceramic surface treatment on the microtensile bond strength between a resin cement and an alumina-based ceramic, J. Adhes. Dent. 6 (2004) 327-332.

[16] Y. Tsuo, K. Yoshida, M. Atsuta, Effects of alumina-blasting and adhesive primers on bonding between resin luting agent and zirconia ceramics, Dent. Mater. J. 25 (2006) 669-674.

[17] M. Kern, V.P. Thompson, Effects of sandblasting and silica-coating procedures on pure titanium, J. Dent. 22 (1994) 300-306.

[18] F. de O. Abi-Rached, R.G. Fonseca, I.G. Haneda, A.A. de Almeida-Júnior, G.L. Adabo, The effect of different surface treatments on the shear bond strength of luting cements to titanium, J. Prosthet. Dent. 108 (2012) 370-376.

[19] M. Özcan, G. Pekkan, A. Khan, Does rinsing following particle deposition methods have a negative effect on adhesion to titanium? J. Adhes. Dent. 15 (2016) 307-310.

[20] R.G. Fonseca, S.B. Martins, F. de Oliveira Abi-Rached, C.A. Dos Santos Cruz, Effect of different airborne-particle abrasion/bonding agent combinations on the bond strength of a resin cement to a base metal alloy, J. Prosthet. Dent. 108 (2012) 316-323.

[21] M.J. Reyes, Y. Oshida, C.J. Andres, T. Barco, S. Hovijitra, D. Brown, Titaniumporcelain system: part III: effect of surface modification on bond strengths, Biomed. Mater. Eng. 11 (2001) 117-136.

[22] Y. Al Jabbari, S. Zinelis, G. Eliades, Effect of sandblasting conditions on alumina retention in representative dental alloys, Dent. Mater. J. 31 (2012) 249-255.

[23] J.P. Bange, L.S. Patil, D.K. Gautam, Growth and characterization of $\mathrm{SiO}_{2}$ films deposited by flame hydrolysis deposition system for photonic device application, Prog. Electromagn. Res. M 3 (2008) 165-175. 
[24] R. Hofman, J.G.F. Westheim, I. Pouwel, T. Fransen, P.J. Gellings, FTIR and XPS studies on corrosion-resistant $\mathrm{SiO}_{2}$ coatings as a function of the humidity during deposition, Surf. Interface Anal. 24 (1996) 1-6.

[25] M.A. Rodriguez MJ. Liso, F. Rubio, J. Rubio, J.L Oteo, Study of the reaction of (-methacryloxypropyltrimethoxysilane) (-MPS) with slate surfaces, J. Mater. Sci. 34 (1999) 3867-3873.

[26] M.J. Walzak, R. Davidson, M. Biesinger, The use of XPS, FTIR,SEM/EDX, contact angle, and AFM in the characterization ofcoatings, JMEPEG 7 (1998) 317-323.

[27] J. Antonucci, S. Dickens, B. Fowler, H.H.K. Xu, W.G. McDonough, Chemistry of silanes: interfaces in dental polymers and composites, J. Res. Natl. Inst. Stand. Technol. 110 (2005) 541-558.
[28] J. Oiu, W.-Q. Yu, F.-O. Zhang, R.J. Smales, Y.-L. Zhang, C.-H. Lu, Corrosion behaviour and surface analysis of a $\mathrm{Co}-\mathrm{Cr}$ and two $\mathrm{Ni}-\mathrm{Cr}$ dental alloys before and after simulated porcelain firing, Eur. J. Oral Sci. 119 (2011) 93-101.

[29] K.J. Kubiak, M.C.T. Wilson, T.G. Mathia, Carval Ph Wettability versus roughness of engineering surfaces, Wear 271 (2011) 523-528.

[30] M. Özcan, E. Yetkiner, Could readily silanized silica particles substitute silica coating and silanization in conditioning zirconium dioxide for resin adhesion, J. Adh. Sci. Tech. 30 (2016) 186-193. 